\title{
MISCDLANEA
}

\section{DIÁLOGO ENTRE SALUD Y ENFERMEDAD}

\section{Dolors Hinojosa Caballero}

20 de Master en Ciencias de la Enfermería. 2012-2013. Universitat Internacional de Cataluyna.

La enfermedad y la salud representan condiciones del organismo medibles y describibles por algunos parámetros, más o menos objetivas y topológicamente identificables. 
Salud: Yo soy aquella manera de vivir que es jubilosa, autónoma y solidaria.

Enfermedad: A mí se me considera como una avería del cuerpo la cual hay que reparar rápidamente para que el enfermo pueda continuar haciendo su vida habitual.

Salud: Es cierto, nadie te ve como una reacción inteligente del cuerpo y de la mente que puede conducir a que el enfermo recupere el estado de equilibrio del que se había apartado.

Enfermedad: Me da mucha rabia que me confundan con los "síntomas". Es como si vamos al cine y confundiéramos a la pantalla de proyección con el proyector. A cada síntoma físico, le ha precedido un pensamiento, un sentimiento, una creencia negativa, algo que nos ha hecho sentirnos mal.

Salud: Es algo que repito todos los días, no es posible cambiar el contenido de una película actuando sobre la pantalla. Tendríamos que recurrir a la cinta y al proyector. Recurrir a las ideas negativas, a los pensamientos sombríos, a la dejadez, al abandono. Todo eso, convenientemente trabajado, modifica el estado de la pantalla de proyección que es nuestro cuerpo.

Enfermedad: El primer paso hacia la curación consiste en estar dispuestos a aceptar el síntoma, por muy inoportuno que parezca. A escucharlo, reconocerlo y descubrir, ayudado por el lenguaje del cuerpo, la verdadera causa que lo ha originado.

Salud: Cuando el enfermo habla de sus síntomas corporales, siempre nos está informando sobre un problema psíquico. Por ejemplo: 
"No lo veo claro".

"Estoy hasta las narices".

"Voy de cabeza".

"No pude frenar a tiempo".

"No lo puedo tragar".

"Cuando lo veo se me revuelve el estómago".

Enfermedad: El síntoma es la manifestación física de algo que rechazamos en el interior. Casi siempre nos obliga a modificar una conducta para corregir nuestro desequilibrio y eso es bueno para la evolución. Nos obliga a actuar. 